\title{
Individual differences in attitudes towards uncertainty: evidence for multiple latent profiles
}

\author{
Maria A. Chumakova ${ }^{a}$, Sergey A. Kornilov ${ }^{b}$ \\ ${ }^{a}$ Moscow City University of Psychology and Education, Moscow, Russia \\ ${ }^{b}$ Lomonosov Moscow State University, Moscow, Russia
}

\begin{abstract}
This paper presents the results of an empirical study investigating individual differences in tolerance and intolerance for uncertainty, using a multidimensional approach. We hypothesized that individual differences in attitudes towards uncertainty are rooted in expectations regarding different sources and subjective evaluations of uncertainty. The results of structural equation modeling and latent profile analysis largely supported these hypotheses. Importantly, latent profile analysis identified four distinct profiles of attitudes towards uncertainty that represented, in addition to classically understood tolerance and intolerance for uncertainty, intolerance for uncertainty with respect to different sources of uncertainty (environment vs. personal relationships).
\end{abstract}

Keywords: uncertainty, tolerance for uncertainty, latent profile analysis, dynamic regulative systems

\section{Introduction}

Every act of decision-making is deeply intertwined with ability to cope with uncertainty (Kornilova, 2011, 2013). Correspondingly, the traits of tolerance/intolerance for uncertainty/ambiguity are typically described as key traits explaining individual differences in decision making (McLain, 1993; Furnham, 1994; Greco \& Roger, 2001; Shalaev, 2007; Kornilova, Chumakova, Kornilov \& Novikova, 2010). Thus, perhaps unsurprisingly, the construct of intolerance for uncertainty/ambiguity has a long history in psychology (Frenkel-Brunswick, 1949; Budner, 1962) and remains both popular and useful in different subfields of psychological inquiry, in particular those that examine decision-making in a variety of different contexts (Grenier, Barrette \& Ladouceur, 2005; Bardi, Guerra \& Ramdeny, 2009; Furnham \& Marks, 2013).

The seminal empirical studies conducted by Frenkel-Brunswick (1949) indicated that intolerance for cognitive ambiguity was closely related to denial of emotional ambivalence. Frenkel-Brunswick studied a sample of children who demonstrated rigid social dichotomizing and ethnic prejudice, and found that these children also tended to display behavioral rigidity in a variety of tasks, including memory and 
perceptual tasks. These findings prompted other researchers to examine the construct of intolerance for uncertainty as a unitary and unidimensional trait reflecting both personal and cognitive components. Since then there have been several attempts to develop an omnibus measure of intolerance / tolerance for uncertainty (Budner, 1962; McLain, 1993). However, put together the measures developed to date have been reported to have significantly lower reliabilities than measures of other personal traits, for example measures of the Big Five (Furnham, 1994; Benjamin, Riggio \& Mayes, 1996; Shalaev, 2007; Kornilova et al, 2010; Bors, Gruman \& Shukla, 2010). We believe that these low reliabilities reported in multiple studies provide tentative evidence for the multidimensional nature of the construct of tolerance/intolerance for uncertainty. Thus, the current paper presents the results of a study that directly investigated whether intolerance for uncertainty is best conceptualized as a unidimensional trait or as a multidimensional complex trait.

Historically, the development of the concept of intolerance for uncertainty has been closely tied to attempts to explain certain attitudes towards differences and novelty in the post-World War II world. An intolerant person was described as having black-or-white thinking, displaying high levels of psychological rigidity, being avoidant of uncertainty, and even undertaking aggressive attempts to "fight" and resist things that could be considered novel or unusual (Frenkel-Brunswick, 1949; Budner, 1962). This description was taken to represent the negative pole on a single continuum of intolerance/tolerance for uncertainty, with the opposite characteristics describing individuals who can be considered to be tolerant of uncertainty. Before presenting an alternative to this unidimensional view of the construct, we would like to briefly focus on three main lines of reasoning and evidence that substantiate it.

Firstly, significant changes came about during the middle of the 20th century in a multitude of life domains. These changes necessitate a reconceptualization of the notion of tolerance/intolerance for uncertainty. Thus, one of the major characteristics of the changing world is a pervasive and rapid increase in the total amount of available information. This increase, coupled with cross-cultural interactions in the context of globalization, has underscored the necessity for studying attitudes towards uncertainty, given the sheer number of opportunities for facing uncertainty in the modern world. Traits typically associated with tolerance for uncertainty (such as flexibility, mobility, and creativity) are now explicitly considered to be essential for occupational success. Finally, the notion of tolerance itself has undergone a reconceptualization as a universal human value. Taken together, these considerations suggest that tolerance/intolerance for uncertainty might not necessarily be a "domain-general" unidimensional trait. One can easily imagine someone who appreciates uncertainty in their professional activity, manifested in persistent attempts to solve difficult and complex problems, risk-taking, etc. However, that same person might not be able to cope with uncertainty in personal relationships, manifested, for example, in increased attempts to control the partner, or the experiencing of negative emotions related to the unpredictability of other people's behavior. Should such a profile be considered characteristic of being intolerant to uncertainty? The unidimensional model of tolerance/intolerance for uncertainty cannot account for these multiple manifestations of attitudes towards uncertainty in different domains. 
Secondly, we would like to focus on the close relationship between uncertainty and information-seeking as a specific strategy for overcoming it. When a person faces a lack of clarity with respect to a particular situation, they can try to remedy this by collecting additional information on the key causal factors and potential solutions of the problem, and their consequences, etc. While sometimes this strategy is ineffective, it is essential in a wide variety of situations and has, in fact, been considered a fundamental human motive (Kagan, 1972) that is core to cognitive activity in general. In parallel with the previous paragraph, we could therefore ask another question: is utilizing information-seeking strategies characteristic of being tolerant or intolerant, or of uncertainty?

Finally, the third foundation of our investigation is the set of empirical findings recently reported by Kornilova and her group (Kornilova et al, 2010). Crucially for our study, using structural equation modeling, Kornilova and colleagues showed that the trait of tolerance/intolerance for uncertainty is best conceptualized as having at least two dimensions, manifested in two latent variables - one of intolerance for uncertainty, and one of acceptance of uncertainty. The presence of two distinct (albeit related) latent factors has been demonstrated in several studies utilizing different samples and different psychodiagnostic measures. The first latent variable represents the common view of intolerance for uncertainty. The second latent variable is manifested in such observable characteristics as risk taking, openness to new experience, and holding a view of uncertainty as an opportunity for development and self-expression.

Thus, we also propose viewing tolerance and intolerance for uncertainty as two different complex patterns of cognitive, emotional and behavioral attitudes that are not reducible to a unidimensional trait (Greco \& Roger, 2001; Grenier, Barrette \& Ladouceur, 2005; Kornilova et al, 2010). At the same time, we suggest that there exist relatively stable, quantifiable individual differences in these attitudes that play a role in a variety of domains and outcomes, and that the spectrum of individual differences in these patterns should be (but, to the best of our knowledge, has not been to date) studied empirically.

Thus, the main aim of our study was to examine the psychological texture of attitudes towards uncertainty. These attitudes reflect internal representations of uncertainty that are presumably built on the basis of evaluating the environment with respect to certain characteristics. Thus, a particular task, situation or environment can be classified as uncertain if it is complex, novel, and unpredictable (with respect to consequences). When a situation exhibits these characteristics, it is frequently referred to as being a "risk situation", a "creative task", a "prognostic task", etc. However, a situation that is uncertain with respect to these objective characteristics may not necessarily be subjectively represented as such, and vice versa. This could be manifested in ignoring or missing critical contradictions in the ambiguous parameters of the task/environment, or in treating certain parameters as reflecting uncertainty when they do not. Therefore, individual differences in attitudes towards uncertainty could be related to the specifics of the process of transforming the objective parameters of a situation (henceforth, "task"; also see below) into their subjective representation that recognizes the contradictions present in the task (henceforth, "problem"). 
The current study was designed largely on the basis of the functional/leveled framework of regulation of choice and decision-making (as proposed and developed by Kornilova, 2011, 2013). According to this framework, each act of decisionmaking requires personal activity and efforts to "get through" the uncertainty. This personal activity manifests itself in the processes of goal formation which, according to Tikhomirov`s personal meanings theory of thinking along with the results of a set of programmatic studies (Babaeva, Berezanskaya, Vasilyev, Voyskunskiy \& Kornilova, 2009), combine and integrate personal and external/objective levels of activity. Previously, we developed a theoretical model of the regulation of rational choice that integrated different components of the intellectual and personality potential in the set of processes of uncertainty acceptance and goal formation (Chumakova, 2013). We found that the relationships between decision-making strategies and personality and cognitive traits were moderated by the specifics of the task. For example, decision-making strategies in an intellectual task were related to achievement motivation (Chumakova, 2010) while characteristics of situational judgment in the context of interpersonal interactions were related to intraception (Chumakova, 2009). Additional support for this model came from studies that demonstrated the existence of the phenomenon of inversion of decision strategies. These studies found that participants with high levels of risk readiness (Kornilova \& Chudova, 1990) or with high levels of tolerance for uncertainty (Chumakova \& Vedeneeva, 2013) employed information-seeking strategies that can be theoretically linked to intolerance for uncertainty. Within our framework, these findings are explained as being the result of the formation of the regulative system at the time of attempting to find a solution for each specific task. The specifics of levels and components of this regulative system are determined by personal activity in goal-formation based on situational characteristics.

However, there is a substantial accumulated body of data on the predictive power of the general attitude towards uncertainty as a dispositional trait with respect to decision-making strategies and outcomes (Budner, 1962; Grenier, Barrette \& Ladouceur, 2005; Kornilova et al, 2010). At a first glance, these results might seem to contradict the idea of present-moment regulation of decision making. However, we would like to argue that this general attitude towards uncertainty determines the subjective representation of a particular situation as containing uncertainty that has to be overcome or resolved. This representation, in turn, creates a specific goal context for the formation of goals and dynamic regulative systems. Thus, when we investigate individual differences toward uncertainty as a potential component of regulation of decision-making, we need to characterize the non-situation-specific aspects of the subjective representation of an uncertain situation. If subjective uncertainty is "a figure" against "the background" of different situation characteristics (novelty, complexity, etc.), which parameters could describe it?

One of the answers to this question can be found in the separation of the concepts of "task" and "problem" (Tikhomirov, 1984). The problem situation contains a certain contradiction between the desire to solve it, and the absence of readily available solutions or their methods. This contradiction generates uncertainty that needs to be overcome. According to Kagan, "....uncertainty is characterized, in part, by incompatibility between cognitive structures, between cognitive structures and experience, or between cognitive structures and behavior" (Kagan, 1972, p. 
54). The process of transforming a particular situation (the task) into the subjective uncertainty that should be overcome (the problem situation) is linked to the identification of these incompatibilities and contradictions. Critically, when we discuss non-situation-specific attitudes to uncertainty, we effectively need to identify which basic contradictions are fundamental for the general representation of uncertainty.

To identify the parameters that could be used to describe these basic contradictions, we examined several questionnaires aimed at measuring tolerance and intolerance for uncertainty (Budner, 1962; McLain, 1993; Kornilova, 2010). Our initial analysis of the wordings suggested that they tend to contain two major types of questions: the first type focuses on generally uncertain situations, and the second focuses on interpersonal relationships. Therefore, we suggest that the first main component of uncertainty representation is the characterization of the nature of its source. We propose distinguishing three types of such sources: environment, as external circumstances that are personally uncontrolled (Kornilova, 2005); other people's actions, particularly in interpersonal relationships (Frenkel-Brunswick, 1949; Kornilova, 2010; Chumakova, 2009); and internal factors related to decisionmaking criteria* (Kornilova, 2005, 2011, 2013). This conceptualization effectively separates external circumstances from personal relationships, and is supported by recent reports on the intolerance for uncertainty in interpersonal relationships, being a factor relatively independent from general intolerance for uncertainty, as measured by the new tolerance/intolerance for uncertainty questionnaire (NTN; Kornilova, 2010). The emergence of this subscale as a separate factor is suggestive of at least a certain degree of its specificity that cannot be reduced to the general tolerance/intolerance for uncertainty.

Representationally, basic contradictions emerge as a result of the recognized inconsistency between a situation and prior expectations about it, which is reflected in the classic descriptions of intolerance for uncertainty and associated behaviors (Frenkel-Brunswick, 1949; Grenier, Barrette \& Ladouceur, 2005; Bardi, Guerra \& Ramdeny, 2009; Kornilova et al, 2010). For example, an intolerant person might consider complex and new situations to be aversive due to a mismatch between the actual properties of a particular event in the environment, and prior expectations about these properties. A representation of this event is subjectively experienced as a stressful feeling of uncertainty. The same logic can be applied to the second source of uncertainty - other people. In this case, an intolerant person is expecting the relationships to be predictable and controllable. If a particular situation of interpersonal interaction is unclear, or the other person's behavior is unpredictable, this introduces a mismatch between the expectations and the actual properties of the situation. We would like to underscore that we view the two types of expectations mentioned above as relatively independent from each other and, developmentally, largely based on previous experience and emergent belief systems.

In sum, we suggest viewing representational uncertainty as intimately tied to the existence of contradictions between a situation and prior expectations and be-

* This source emerges during the course and process of decision-making and thus cannot be measured with questionnaires as a fixed/dispositional variable. 
liefs about it. However, individual differences in general attitudes to uncertainty are reflective of not only these expectations but also of subjective evaluations of an uncertain situation as threatening, neutral, or attractive (because it provides an opportunity for development and self-realization; Kagan, 1972; McLain, 1993; Greco \& Roger, 2001; Bardi, Guerra \& Ramdeny, 2009; Kornilova, 2010). The combination of representations of basic contradictions and subjective evaluations of uncertainty is crucial for establishing the goal context of coping with objectively uncertain situations, which in turn is realized in strategies that lead to avoidance/reduction or acceptance/overcoming of uncertainty in each specific situation.

Thus, the current study investigated whether individual differences in tolerance/intolerance for uncertainty could be at least partially explained by the existence of multidimensional individual differences in attitudes towards uncertainty that are linked to representations of uncertainty, specifically, expectations about environment and interpersonal relationships and the evaluation of uncertainty as threatening or attracting.

\section{Methods}

For this study, we recruited a total of 438 undergraduate students (psychology majors) at Lomonosov Moscow State University ( 83 men; the ages ranged from 17 to 46 years, $M=20.4, S D=3.6$ ).

We used three questionnaires to measure tolerance/intolerance to uncertainty and associated traits:

1. New questionnaire for tolerance to uncertainty (NTN; Kornilova, 2010). NTN is a questionnaire that measures three related traits: general tolerance for uncertainty, general intolerance for uncertainty, and interpersonal intolerance for uncertainty.

2. Multiple Stimulus Types Ambiguity Tolerance-I (MSTAT-I) (McLain, 1993). MSTAT-I is a brief questionnaire that measures general tolerance for uncertainty.

3. Personal factors of decision-making (LFR; Kornilova, 2003). LFR is a personality questionnaire that is aimed at measuring risk readiness and rationality (defined as information seeking).

\section{Results}

To investigate the dimensionality of tolerance/intolerance for uncertainty, we first analyzed the data from three questionnaires using item-level data. Specifically, in the first step of our analysis, we classified all of the items found across the three questionnaires in terms of expectations about the environment and relationships, and the subjective evaluation of uncertainty. Thus, each item was classified as being representative of one of the four following hypothesized factors:

1. Expectations about personal relationships (items that place emphasis on the value of predictability in personal relationships; E-PR).

2. Expectations about the environment (with a general emphasis on clarity and lack of contradictions; E-EV). 
3. A generally negative view of uncertainty as a threatening circumstance (items describing negative emotions and/or avoidant behavior; Uncertainty as a Threat, S-UT).

4. A generally positive view of uncertainty (items describing positive emotions and/or a proactive desire to "deal with" or approach it; Attractiveness of Uncertainty, S-AU).

Table 1. A pooled set of items from three questionnaires selected for the analysis

\begin{tabular}{|c|c|}
\hline Factor & Item wording \\
\hline $\begin{array}{l}\text { Expectations about } \\
\text { personal relation- } \\
\text { ships }\end{array}$ & $\begin{array}{l}\text { I try to avoid situations which are ambiguous (MSTAT-2) } \\
\text { I dislike ambiguous situations (MSTAT-16) } \\
\text { I'm just a little uncomfortable with people unless I feel that I can } \\
\text { understand their behavior (NTN-8) } \\
\text { I get pretty anxious when I'm in a social situation over which I have } \\
\text { no control (NTN-10) } \\
\text { It bothers me when I am unable to follow another person's train of } \\
\text { thought (NTN-11) } \\
\text { It bothers me when I don't know how other people react to me (NTN-13) }\end{array}$ \\
\hline $\begin{array}{l}\text { Expectations about } \\
\text { the environment }\end{array}$ & $\begin{array}{l}\text { I have always felt that there is a clear difference between right and } \\
\text { wrong (NTN-12) } \\
\text { A good job is one where what is to be done and how it is to be done } \\
\text { are always clear (NTN-22) } \\
\text { What we are used to is always preferable to what is unfamiliar (NTN-24) } \\
\text { The sooner we all acquire similar values and ideas the better (NTN-27) }\end{array}$ \\
\hline $\begin{array}{l}\text { Uncertainty as a } \\
\text { Threat }\end{array}$ & $\begin{array}{l}\text { I try to avoid situations which are ambiguous (MSTAT-6) } \\
\text { I am good at managing unpredictable situations (reverse-scored item) } \\
\text { (MSTAT-7) } \\
\text { I'm tolerant of ambiguous situations (reverse-scored item) (MSTAT-11) } \\
\text { I enjoy tackling problems that are complex enough to be ambiguous } \\
\text { (reverse-scored item) (MSTAT-12) } \\
\text { I try to avoid problems that don't seem to have only one "best" solu- } \\
\text { tion (MSTAT-13) } \\
\text { I pursue problem situations which are so complex some people call } \\
\text { them "mind-boggling" (reverse-scored item) (MSTAT-19) }\end{array}$ \\
\hline $\begin{array}{l}\text { Attractiveness } \\
\text { of Uncertainty }\end{array}$ & $\begin{array}{l}\text { I prefer familiar situations to new ones (reverse-scored item) } \\
\text { (MSTAT-8) } \\
\text { I often find myself looking for something new, rather than trying to } \\
\text { hold things constant in my life (MSTAT-14) } \\
\text { I generally prefer novelty over familiarity (MSTAT-15) } \\
\text { I prefer a situation in which there is some ambiguity (MSTAT-22) } \\
\text { I can easily and willingly take big risks (LFR-10) } \\
\text { I like to fool around with new ideas, even if they turn out later to be a } \\
\text { total waste of time (NTN-17) } \\
\text { What we are used to is always preferable to what is unfamiliar (NTN-24) }\end{array}$ \\
\hline
\end{tabular}

A total of 22 items were selected by two experts from the pool of 76 items, as being reflective of the hypothesized latent factors (see Table 1). In the second step of analysis, we tested the overall theoretical model proposed in this paper using confirmatory factor analysis as implemented in EQS v. 6.1 for Windows 
(Bentler, 1995). Initially, each of the items only loaded on one corresponding latent variable. However, the examination of model modification indices suggested that some cross-loadings and error covariances could significantly improve the fit of the model. Each of the suggested modifications was examined, and only those that fitted the theoretical framework and/or represented an overlap between specific item wordings were included. The final model included four latent variables. Covariances among latent variables and factor loadings (except for those fixed to 1 for the purpose of model identification and latent variable scaling, i.e., one per each latent variable) were estimated freely. The modified model (presented in Figure 1) displayed an overall satisfactory fit: $\chi^{2}(199)=402.28, p<.001$, CFI $=.92$, RMSEA $=.048$, SRMR $=.05$, suggesting that the items could be viewed as representing the hypothesized four-variable latent structure.

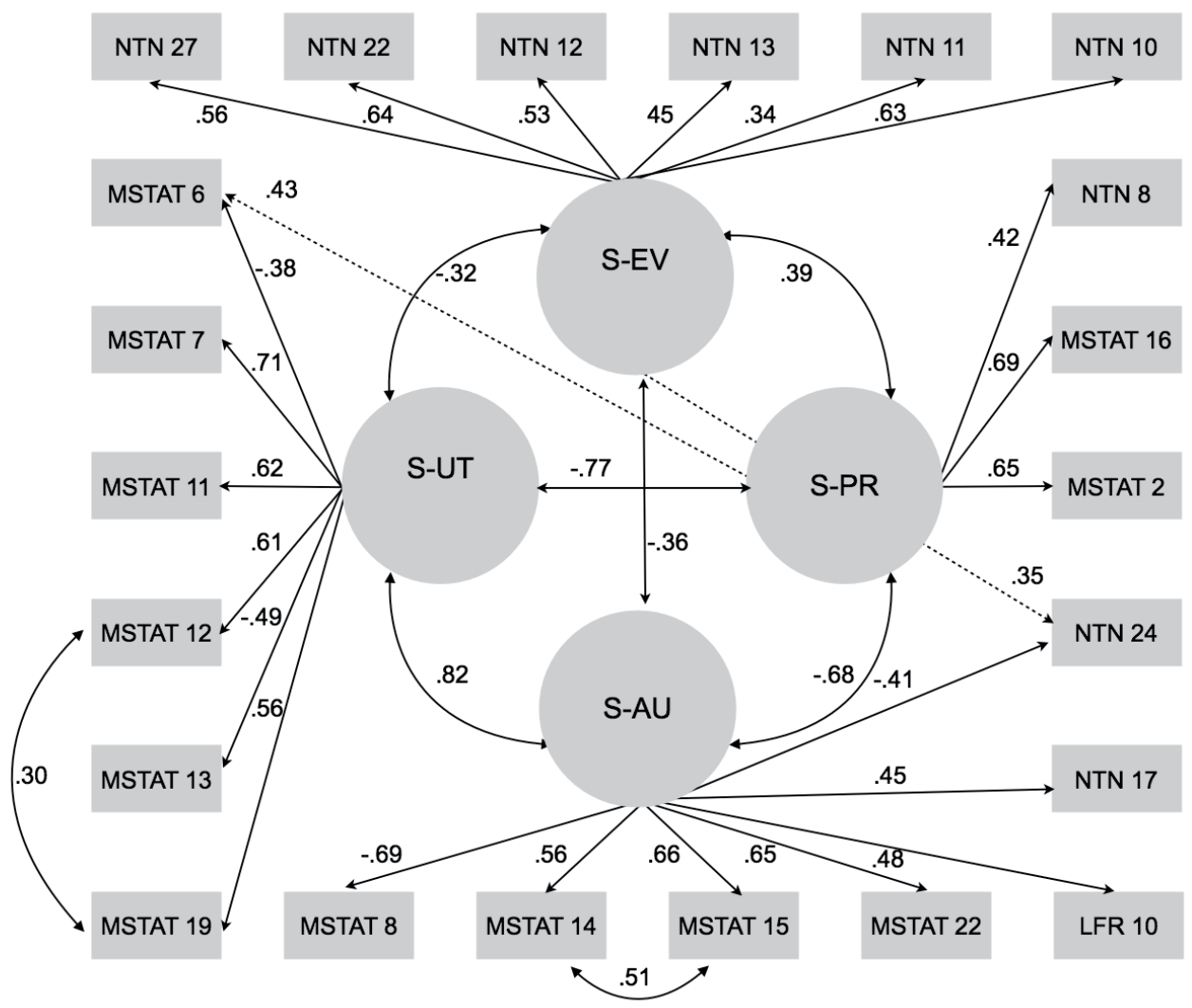

Figure 1. The main CFA model tested in the study

In the third step we used a person-centered approach technique, latent profile analysis (Fraley, Raftery, 2007), to identify latent profiles of attitudes towards uncertainty based on the scores obtained for the four factors described above. Since latent profile analysis is a model-based technique, the fit of each potential profile configuration was tested and compared to the fit of alternative models. We tested the fit of a total of 100 different models that differed in number of latent profiles (from 1 to 10) and other parameters, such as the equal vs. unequal variances across profiles, equal vs. unequal sizes of the latent profiles, etc. The values of the Bayesian Information 
Criterion (BIC) for each of the models are presented in Figure 2. The best fit was obtained for the 4-profile solution that had the highest BIC value, suggesting that the participants in the study can be classified as having one of the four presumably stable latent profiles of attitudes towards uncertainty (see Figures 3 and 4).

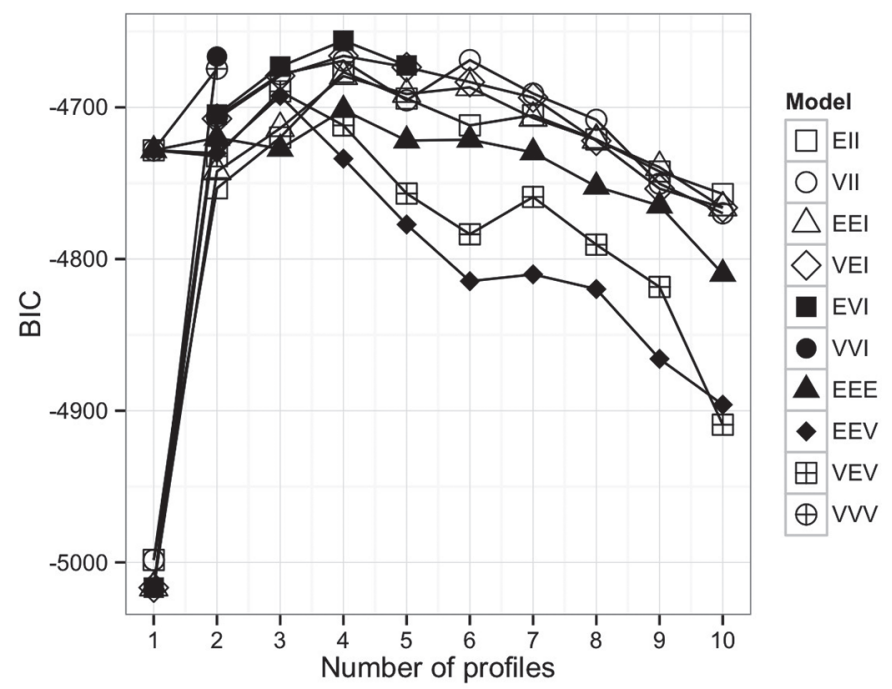

Figure 2. Fit indices of the tested latent profile models

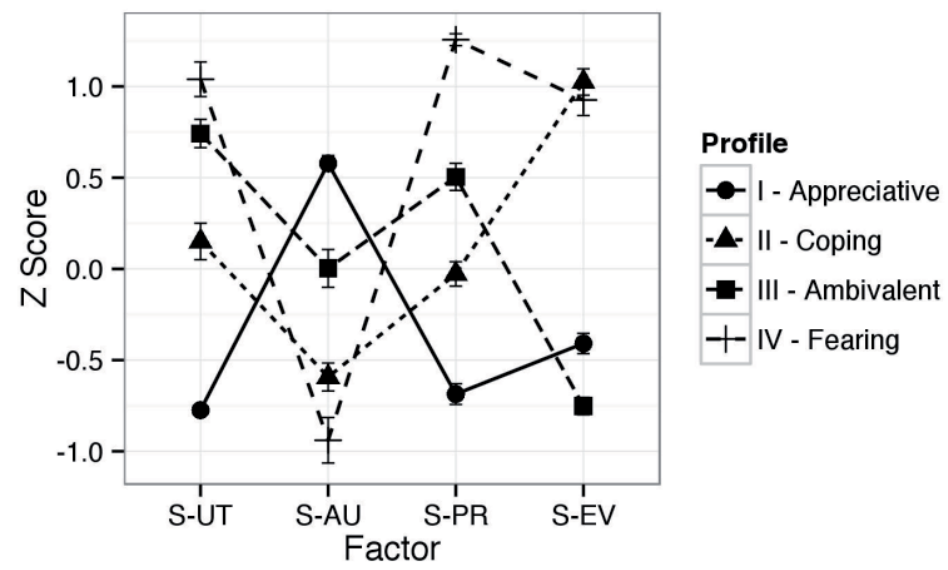

Figure 3. Average factor scores of the four latent profiles

Overall, Profile I was the most numerous, followed by Profiles III, II, and IV (Figure 4). Profile I ("Appreciative") was characterized by relatively weak expectations of predictability from both the environment and personal relationships, and an overall positive evaluation of uncertainty. Profile II (“Coping”) was characterized by relatively weak expectations of predictability with respect to personal relationships, strong expectations of clarity and predictability from the environment in general, a moderate evaluation of the threat coming from uncertainty, and low levels of attraction to it. Profile III ("Ambivalent") was characterized by strong expectations of predictability with respect to personal relationships, and weak expectations of predictability with 
respect to the environment in general. This profile tended to view uncertainty as both threatening and mildly attractive. Profile IV ("Fearing") was characterized by strong expectations of clarity and predictability across the two sources of uncertainty, and a negative view of uncertainty as an overall threatening circumstance.

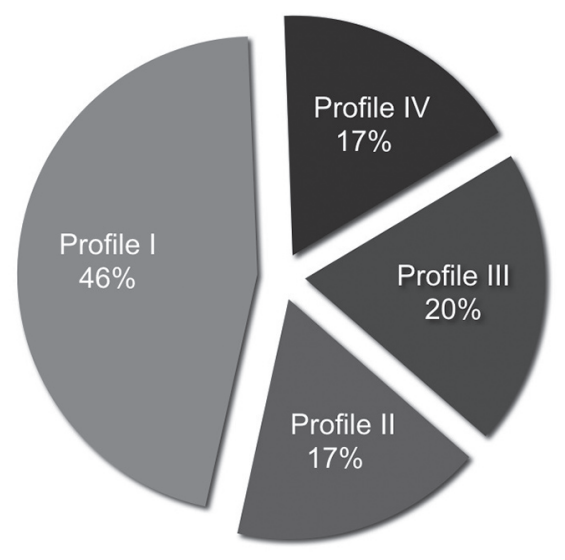

Figure 4. The distribution of the four latent profiles in the sample

We also examined gender distributions across different latent profiles, and found that they differed across profiles, $\chi^{2}(3)=8.439, p=.038$. While Profiles I and IV were represented by a similar number of women and men, Profile II was more characteristic of men, and Profile III was more characteristic of women (Figure 5).

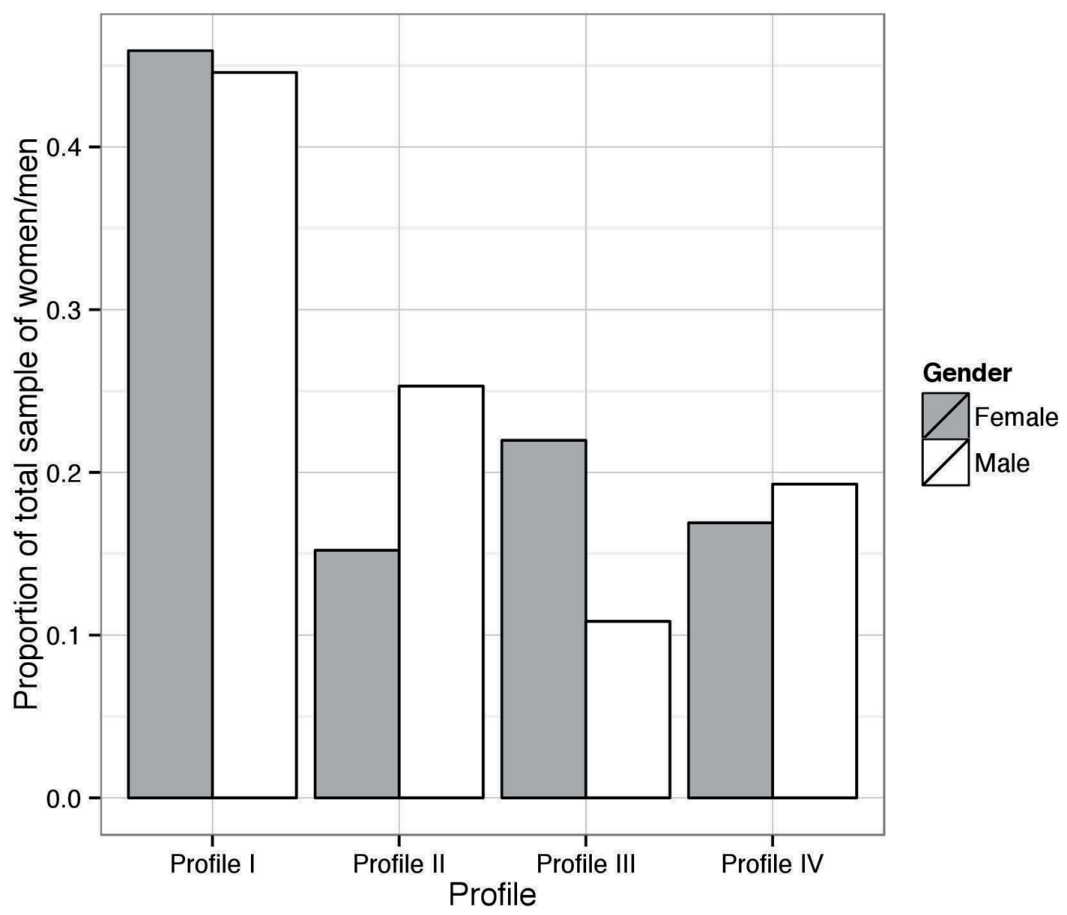

Figure 5. Gender distributions across the four latent profiles 
Finally, we investigated the relationship between the estimated probability of belonging to a certain profile with overall scores obtained using the three administered questionnaires, i.e., general tolerance for uncertainty, general intolerance for uncertainty, interpersonal intolerance for uncertainty, risk readiness, and rationality. These intercorrelations are presented in Table 2.

Table 2. Intercorrelations between study measures and the estimated probability of belonging to each of the four latent profiles

\begin{tabular}{lcccc}
\hline & $\begin{array}{c}\text { Profile I } \\
(\mathbf{p})\end{array}$ & $\begin{array}{c}\text { Profile II } \\
(\mathbf{p})\end{array}$ & $\begin{array}{c}\text { Profile } \\
\text { III (p) }\end{array}$ & $\begin{array}{c}\text { Profile IV } \\
(\mathbf{p})\end{array}$ \\
\hline Tolerance for uncertainty (NTN) & $.377^{* *}$ & $-.262^{* *}$ & .084 & $-.335^{* *}$ \\
General intolerance for uncertainty (NTN) & $-.266^{* *}$ & $.338^{* *}$ & $-.266^{* *}$ & $.294^{* *}$ \\
Interpersonal intolerance for uncertainty (NTN) & $-.553^{* *}$ & .091 & $.117^{*}$ & $.532^{* *}$ \\
Tolerance for uncertainty (MSTAT) & $.762^{* *}$ & $-.161^{* *}$ & $-.281^{* *}$ & $-.584^{* *}$ \\
Risk readiness (LFR) & $.425^{* *}$ & -.028 & $-.171^{* *}$ & $-.369^{* *}$ \\
Rationality (LFR) & $-.255^{* *}$ & $.131^{* *}$ & -.010 & $.223^{* *}$ \\
\hline
\end{tabular}

${ }^{\star}-p<.05 ;{ }^{* *}-p<.01$

We found that Profile I was positively related to tolerance for uncertainty and risk readiness, and negatively related to general intolerance for uncertainty, interpersonal intolerance for uncertainty, and rationality. These results suggest that individuals with Profile I exhibit traits that correspond to the traditional descriptions of tolerance for uncertainty. Profile IV was negatively related to tolerance for uncertainty and risk readiness, and positively related to both types of intolerance for uncertainty (general and interpersonal) and rationality, suggesting that individuals with Profile IV exhibit traits characteristic of the conventionally understood intolerance for uncertainty.

Profile II was negatively related to tolerance for uncertainty, and was positively related to general intolerance for uncertainty and rationality. However, this profile was not related to either interpersonal intolerance for uncertainty or risk readiness, supporting the idea of the independence of attitudes towards uncertainty with respect to the environment and with respect to personal relationships.

Profile III was negatively related to risk readiness and tolerance for uncertainty measured with MSTAT-I but not NTN. This profile was also negatively related to general intolerance for uncertainty, positively related to interpersonal intolerance for uncertainty, and independent of rationality. Thus, Profile III is simultaneously negatively related to both tolerance and intolerance for uncertainty. We suggest that these results cannot be explained by a unidimensional model of intolerance for uncertainty, and necessitate a multidimensional approach that explicitly distinguishes different sources of uncertainty. 


\section{Discussion}

One of the most important results of this study was establishing the existence of four different latent profiles that characterize attitudes towards uncertainty with respect to expectations about different sources of uncertainty (personal relationships and environment) and subjective evaluations of uncertainty (negative and positive).

The first latent profile ("Appreciative" or adaptive) is characterized by an overall low desire for clarity across both sources of uncertainty. Individuals with this profile are unlikely to view uncertainty as threatening and likely to view it (and the corresponding complex novel situations) as a challenging opportunity for selfexpression and development. They accept the fundamental existence of contradictions in the environment, and are both ready and equipped to deal with them. Similarly, they do not necessarily expect other people's behavior to be completely predictable. Therefore, this attitudinal profile can effectively be labeled as characteristic of a "tolerant" person.

The fourth latent profile ("Fearing") is the direct opposite of the first profile. Individuals with this profile have stronger expectations for both the environment and relationships to be clear, predictable, and simple. They dislike uncontrollable and unpredictable situations, and are likely to feel threatened when such situations arise. They also tend to show lower risk readiness and higher interpersonal intolerance for uncertainty. Overall, this profile can be directly mapped onto the classical descriptions of an intolerant person.

The two remaining profiles are revealing with respect to the importance of differentiating expectations about different sources of uncertainty in understanding attitudes towards uncertainty. The second profile ("Coping") is characterized by a strong desire for the environment to be simple and clear (similar to what is observed for the "Fearing" latent profile) and by mild expectations of predictability and clarity in personal relationships. Individuals with this profile do not view uncertainty as either particularly attractive or threatening. Interestingly, there was no correlation between this profile and risk readiness. This suggests that risk-taking in individuals holding this profile is rather situation-specific. We also did not find a significant correlation of this profile with interpersonal intolerance for uncertainty, thus supporting our hypothesis about the partial representational independence of different sources of uncertainty.

The third profile ("Ambivalent") is characterized by low expectations of simplicity from the environment, but a relatively high desire for predictability and clarity in personal relationships. We labeled this profile "Ambivalent" because individuals holding this profile were likely to view uncertainty as simultaneously attractive and threatening. In fact, their scores on these two factors were close to the scores of individuals who held the first and fourth profiles. This profile was not related to rationality defined as information-seeking, which suggests that the use of this strategy is situation-specific rather than being a general coping strategy. This profile was also significantly but differentially related to different types of intolerance for uncertainty: i.e., it was positively related to interpersonal intolerance for uncertainty and negatively related to general intolerance for uncertainty. Taken together, 
these results provide some support for our hypothesis about the differential roles of specific sources of uncertainty in attitudes towards it.

Finally, we found significant differences in gender distributions across the four profiles. The "Appreciative" and "Fearing" profiles were equally characteristic of male and female participants. However, we found gender imbalances for the "Coping" and the "Ambivalent" profiles. The "Coping" profile can be considered more characteristic of men, and the "Ambivalent" profile can be considered more characteristic of women. The presence of these gender imbalances suggests that gender plays a role in the development of particular profiles of attitudes towards uncertainty. That gender imbalances were found for these two profiles is particularly important in the context of revealing the gender-differential effects of sociocultural influences on the development of expectations about the two major sources of uncertainty.

\section{Conclusion}

The current study revealed the existence of four different profiles of attitudes towards uncertainty. Among these four profiles, we found a general profile of a tolerant person and three distinct profiles of an intolerant person, which differed with respect to their attitudes towards different sources of uncertainty, and subjective evaluations of uncertainty.

We suggest that different representations of uncertainty (which include objective and subjective components) create specific goal contexts that define the process of goal formation. However, we do not believe that differences in representations of uncertainty necessarily rigidly determine which strategies will be employed in dealing with or resolving the uncertainty, given the openness of dynamic regulation systems in decision making (Kornilova, 2013).

Further research should examine behavioral differences among these four profiles in decision-making in specific situations. We are currently conducting a study that is explicitly looking at these differences, and has the potential to advance our understanding of the trait(s) of tolerance/intolerance of uncertainty and its involvement in decision-making. Another potentially fruitful avenue of research would be to study factors that play a role in the development of uncertainty attitudes with respect to the environment and personal relationships (e.g., factors such as family context and previous experience) and their relationships with decision-making strategies. Finally, we are currently in the process of conducting another study that aims to link the identified latent profiles of attitudes towards uncertainty to a host of cognitive and personality traits in the context of a broader research program within the Dynamic Regulative Systems framework (Kornilova, 2013).

\section{Acknowledgements}

This study and the preparation of this publication were supported by the Russian Foundation for Humanities (RGNF; project N13-36-01254). 


\section{References}

Babaeva, U.D., Berezanskaya, N.B., Vasilyev I.A., Voiskounsky, A.E., Kornilova, T.V. (2009). O vklade O.K. Tihomirova v metodologiyu, teoriyu i eksperimentalnuyu praktiku psihologicheskoy nauki [O.K. Tikhomirov's contribution to methodology, theory, and practice of experimental psychology]. Metodologiya i istoriya psihologii [Methodology and History of Psychology], 4(4), 9-27.

Bardi, A., Guerra, V.M., Ramdeny, G.S.D. (2009). Openness and ambiguity tolerance: Their differential relationships to well-being in the context of an academic life transition. Personality and Individual Differences, 47, 219-223. doi: 10.1016/j.paid.2009.03.003

Benjamin, A.J., Riggio, R.E., Mayes, B.T. (1996). Reliability and Factor Structure of Budner's Tolerance for Ambiguity Scale. Journal of Social Behavior and Personality, 11 (3), 625-632.

Bentler, P.M. (1995). EQS structural equations program manual. Encino, CA: Multivariate Software.

Bors, D.A., Gruman J.A., Shukla S (2010). Measuring tolerance of ambiguity: Item polarity, dimensionality, and criterion validity. Revue européenne de psychologie appliqué, 60, 239-245. doi: 10.1016/j.erap.2010.07.001

Budner, S. (1962). Intolerance of ambiguity as a personality variable. Journal of Personality, 30, 29-40. doi: 10.1111/j.1467-6494.1962.tb02303.x

Chumakova, M.A. (2009). Motivaciya i prakticheskiy intellekt $v$ funkcionalnoy regulyacii racionalnogo vibora [Motivation and practical intelligence in functional regulation of rational choice]. Vestnik Tambovskogo universiteta. Seriya: Gumanitarny'e nauki [Bulletin of Tambov University, Series Humanities], 9(77), 264-268.

Chumakova, M.A. (2010). Intellektualno-lichnostnaya regulyaciya v reshenii zadach na konstruirovanie [Intellectual and personal regulation of solving constructing problems]. Voprosy psihologii [Issues of Psychology], 4, 83-93.

Chumakova, M.A. (2013). Lichnostnaya regulyaciya racionalnogo vibora: razvitie idei edinstva intellekta i affekta [Personality regulation of rational choice: developing the idea of the unity of intellect and affect]. Psihologicheskiy jurnal [Psychological journal], 34(3), 119-125.

Chumakova, M.A., Vedeneeva, N.V. (2013). Ispolzovanie dopolnitelnoy informacii pri preodolenii neopredelennosti v situacii mezhlichnostnogo vzaimodejstviya [The use of additional information in the process of coping with uncertainty in the situation of interpersonal interaction]. Idei O.K. Tihomirova i A.V. Brushlinskogo i fundamentalnie problemi psihologii ( $k$ 80-letiyu so dnya rozhdeniya). Materiali Vserossiyskoy nauchnoy konferencii (s inostranny'm uchastiem). Moskva, 30 maya - 1 iyunya $2013 \mathrm{~g}$ [O.K. Tihomirov's and A.V. Brushlinskiy's ideas and fundamental problems of psychology (the 80th anniversary of the birth). All-Russian Scientific Conference (with foreign participation). Moscow, May 30 - June 1, 2013], Moscow University Press, 151-154.

Fraley, C., Raftery, A. (2007). Model-based Methods of Classification: Using the mclust Software in Chemometrics. Journal of Statistical Software, 18(6). Retrieved from http://www.jstatsoft. org/v18/i06

Frenkel-Brunswick, E. (1949). Intolerance of ambiguity as an emotional and perceptual personality variable. Journal of Personality, 11(1), 108-143. doi: 10.1111/j.1467-6494.1949. tb01236.x

Furnham, A. (1994). A content, correlation and factor analytic study of four tolerance of ambiguity questionnaires. Personality and Individual Differences, 16, 403-410. doi: 10.1016/01918869(94)90066-3

Furnham, A., Marks, J. (2013). Tolerance of Ambiguity: A Review of the Recent Literature. Psychology, 4, 717-728. doi: 10.4236/psych.2013.49102 
Greco, V., Roger, D. (2001). Coping with uncertainty: the construction and validation of a new measure. Personality and Individual Differences, 31, 519-534. doi: 10.1016/S0191-8869(00)00156-2

Grenier, S., Barrette, A.-M., Ladouceur, R. (2005). Intolerance of Uncertainty and Intolerance of Ambiguity: Similarities and differences. Personality and Individual Differences, 39, 593-600. doi: $10.1016 /$ j.paid.2005.02.014

Kagan, J. (1972). Motives and development. Journal of Personality and Social Psychology, 22(1), 51-66. doi: 10.1037/h0032356

Kornilova, T.V. (2003). Psihologiya riska i prinyatiya resheniy [Psychology of risk and decision making]. Moscow: Aspekt Press.

Kornilova, T.V. (2005). Metodologicheskie problemi psihologii prinyatiya reshenij [Methodological problems of psychology of decision making]. Psihologicheskiy jurnal [Psychological journal], 26(1), 7-17.

Kornilova, T.V. (2010). Noviy oprosnik tolerantnosti k neopredelennosti [New questionnaire for tolerance to uncertainty]. Psihologicheskiy jurnal [Psychological journal], 31(1), 74-86.

Kornilova, T.V. (2011). Dinamicheskoe funkcionirovanie intellektualno-lichnostnogo potenciala cheloveka $\mathrm{v}$ psichologicheskoy regulyacii resheniy i viborov [Dynamic functioning of intellectual and personal potential in psychological regulation of decisions and choices]. Vestnik Moskovskogo univerciteta, Seria 14, Psihologiya [Moscow University Psychology Bulletin], 1, 66-79.

Kornilova, T.V. (2013). Psihologiya neopredelennosti: Edinstvo intellektualno-lichnostnoy regulyacii resheniy i viborov [Psychology of Ambiguity: Unity of intellectual and personal regulation of decisions and choices]. Psihologicheskiy jurnal [Psychological journal], 34(3), $89-100$.

Kornilova, T.V., Chudina, T.V. (1990). Lichnostnie i situacionnie faktori prinyatiya reshenij v usloviyah dialoga s EVM [Personal and situational factors in decision-making dialogue with a computer]. Psihologicheskiy jurnal [Psychological journal], 11(4), 32-37.

Kornilova, T.V., Chumakova, M.A., Kornilov, S.A., Novikova, M.A. (2010). Psihologiya neopredelennosti: Edinstvo intellektualno-lichnostnogo potenciala cheloveka. [Psychology of Uncertainty: Unity of human intellectual and personal potential]. Moscow: Smisl.

McLain, D.L. (1993). The MSTAT-I: A new measure of an individual`s tolerance of ambiguity. Educational and Psychological Measurement, 53(1), 183-189. doi: 10.1177/0013164493053 001020

Shalaev, N.V. (2007). Tolerantnost k neopredelennosti v psihologicheskih teoriyah [Tolerance for uncertainty in psychological theories]. Chelovek $v$ situacii neopredelennosti [Person in a situation of uncertainty], Moscow: TEIS, 9-33.

Tikhomirov, O.K. (1984). Psihologiya myshleniya [Psychology of thinking]. Moscow University Press.

Received: 29 September 2013

Accepted: 10 November 2013 